\title{
Incorporating SPOCs Platform in Innovation and Entrepreneurship Education \\ Shengbo Shi
}

\author{
School of Information Science and Technology, Zhejiang Shuren University, Hangzhou, 310015, \\ China \\ workshirley@yeah.net
}

Keywords: SPOCs; Innovation and Entrepreneurship; Curriculum and practice system; Teaching methods; Evaluation mechanism

\begin{abstract}
Innovation and entrepreneurship education has become an important part of higher education reform. This paper discusses the possibility of the SPOCs platform incorporated into innovation and entrepreneurship education, and further studies the relevant curriculum and practice system, teaching methods and evaluation mechanism. Based on above studies, it initially constructs the mode of innovation and entrepreneurship education based on SPOC platform.
\end{abstract}

\section{Introduction}

Innovation and entrepreneurship play important roles in promoting technical progress and economic growth. Adjusted by economic society, introducing innovation and entrepreneurship education in universities has become one of the important tasks in Chinese higher education reform. Although innovation and entrepreneurship education has been started up for almost one decade in China, it is still in its early stages with not good performance in cultivating innovative and entrepreneurial talents. In fact, in traditional higher education mode, there are a lot of challenges to cultivate and improve students' the innovation and entrepreneurship ability, which are summarized as below: 1) In traditional higher education mode, innovation and entrepreneurship education is always independent from professional education. 2) In traditional higher education mode, teaching-centered innovation and entrepreneurship education is often relegated as "empty talk". 3) In traditional higher education mode, innovation and entrepreneurship education is lack of practice system.

From an overall perspective, the current innovation and entrepreneurship education in universities is not systematic, not practical, not pertinent and not hierarchical. Therefore, it is urgent for universities to promote and adopt new measures to deepen innovation and entrepreneurship education reform. In this paper, we introduced SPOCs platform into the reform of innovation and entrepreneurship education. SPOCs (Small Private Online Course) is a new online education technique, that can be widely used in universities. It is advantageous over traditional education mode. So we took SPOCs into consideration to solve the above summarize problems.

This paper is organized as below: Section 1 made an introduction about our research; Section 2 summarized the related work about SPOCs application research and innovation and entrepreneurship education in universities; Section 3 proposed a new innovation and entrepreneurship education mode incorporating with SPOCs platform; Section 4 made a discussion, hoping to advance the innovation and entrepreneurship education reform in universities.

\section{Related Work}

SPOCs in Higher Education. MOOCs (Massive Open Online Course) is a new teaching mode 
that can make worldwide students have access to the same course of the same teacher over the Internet. It successfully attracts public attention because all courses in MOOC platforms are available to anyone and it can help provide life-long learning opportunities. How to make MOOCs incorporate with higher education in universities has become a significant research topic. Armando Fox at UC Berkeley proposed SPOCs, a Small Private Online Course, which is an organic combination of MOOCs technique and classroom education[1]. Comparing to MOOCs, SPOCs is more suitable to be applied in universities. According to our literature review, researches of SPOCs in higher education can be summarized as the following three aspects:

(1) Feature and Connotation of SpOCs. Fox A (2013)[1] firstly proposed and defined SOPCs, which is the marriage of live lecture and MOOC materials, that can both maximize their advantages and minimize their disadvantage. Burge J, etc.(2015)[2] showed that we could take MOOCs material to augment the lecture classes. S Jiang (2015)[3] made comparison of MOOCs and SPOCs to show that SPOCs have the features of small-scale, restrictiveness and intensiveness. Hd Yin(2015)[4] proposed that SPOCs is a school-based education platform based on MOOCs, which can make better integration of micro curriculum resources and classroom teaching approach and make it possible for teachers to deeply intervene in the process of students' learning. L Li(2016)[5] presented that SPOCs is the inheritance of MOOCs.

(2) Education Methods Incorporated with SPOCs. SPOCs is an integration of lecture class and on-line courses, so the education methods incorporated with SPOCs may different from the traditional one. QT Hu, etc.(2014) [6] presented that SPOCs is more able to meet the needs of the flipped classroom and mixed teaching approaches. Root(2014)[7] proposed that forming the group discussion forum in the on-line platform can help students better understand the curriculum content, enhance the on-line interaction between students, and produce higher education efficiency and effectiveness. Kulkarni,etc.(2013)[8] verified that the hybrid of self-assessment and peer-assessment mechanism can improve online course performance and enhance self-efficacy, which played a significant role to cultivate the students' abilities.

(3) Practical Application of SPOCs. Researchers also focus on practical application of SPOCs, some of them pay attention to the design and implementation of SPOC platform, while some of them have introduced SPOCs into the specific classroom in universities $[9,10,11]$. SPOCs is a promising directions of on-line platform and shows its good performance to improve education quality by case study.

Innovation and Entrepreneurship Education. Innovation and entrepreneurship education has become an important part of higher education, especially for application-oriented universities. Harvard University is the first one to carry out the innovation and entrepreneurship education in the year of 1947. But in China,it began in the year of 2002, which is still in the exploratory stage. Generally, former researches on innovation and entrepreneurship education are focused on the following aspects:

(1) Connotation and Reform Path of Innovation and Entrepreneurship Education. J Liu(2016) [12]suggested that the connotation of innovation and entrepreneurship education is to cultivate students the entrepreneurship consciousness and innovation spirit, whose basic features are innovation, creation and practice. It is also an effective extension of employment education. YJ $\mathrm{Wu}(2015)$ [13]proposed that the path selection of innovation and entrepreneurship education is to reform the education architecture system, form innovative ability formation mechanism, optimize the support system and improve incentive mechanism in higher education.

(2) Construction of Innovation and Entrepreneurship Education Architecture. L Jiao,etc.(2015) [14] pointed out that the innovation and entrepreneurship education architecture 
mainly included two parts, the curriculum system and the practical system. Practice system is divided into the inside-school practice platform system and the outside-school practice project system. Y Chen(2016) [15] suggested that the innovation and entrepreneurship education architecture includes target system, teaching system, support system and evaluation system.

(3) Comparison on Innovation and Entrepreneurship Education at Home and Abroad. JQ Chang(2008)[16] proposed that the connotation education and system construction should be deepened in the process of innovation and entrepreneurship education in China by comparing and analyzing the innovation and entrepreneurship education in Chinese and American universities. Dirk Reichelt (2015) [17] presented the characteristics of the innovation and entrepreneurship education in Germany, and emphasized the role of the incubator in universities. M Yu(2016)[18] put forward suggestions on teaching staff, curriculum system and competition support according to the innovation and entrepreneurial education experience in Japanese.

\section{Incorporating SPOCs Platform in Innovation and Entrepreneurship Education}

With the increase efforts of Chinese government to promote innovation and entrepreneurship into higher education, innovation and entrepreneurship education attracts more and more universities' attention. In fact, innovation and entrepreneurship education is a systemic project not only just including the curriculum and practice system, but also referring to the teaching methods and evaluation mechanism. In this paper, we introduces SPOCs technique to construct a complete set of innovation and entrepreneurship education system.

Curriculum and Practice System. Innovation and entrepreneurship curriculum and practice system is a basic part of innovation and entrepreneurship education system, which should be constructed in accordance with the following principles. Firstly, innovation and entrepreneurship curriculum and practice system should be integrated into professional education. Secondly, innovation and entrepreneurship curriculum and practical system should be throughout the whole higher education. Thirdly, innovation and entrepreneurship curriculum and practical system should be divided into basic module,elite module and incubation module. Base on the above principles, the curriculum and practice system of innovation and entrepreneurship education incorporating SPOCs platform is shown as Fig. 1.

In SPOCs platform, curriculum and practice system can be divided into online learning part and offline discussion and practice part. Online learning part includes the curriculums that can be autonomic learned by students in SPOCs platform such as basic innovation and entrepreneurship curriculum, professional innovation and entrepreneurship curriculum and synthetic innovation and entrepreneurship curriculum. Basic innovation and entrepreneurship curriculum aims to make students understand and master the basic methods and rules of innovation and entrepreneurship. Professional innovation and entrepreneurship curriculum is a marriage of professional education and innovation and entrepreneurship education, which can be further classified into technology curriculum and qualify curriculum. The aim of professional innovation and entrepreneurship curriculum is to cultivate students innovation and entrepreneurship spirits and abilities based on the profession skill. Synthetic innovation and entrepreneurship curriculum is an advanced course to incubate innovation and entrepreneurship items and support individual professional guidance. Offline Discussion and practice part includes what must be carried out offline such as case study and discussion in classroom, experiments and practices in school labor, academic competition and research items in guidance of the teachers, university-enterprise cooperation platform and incubation platform supported by society. According to the stages of innovation and entrepreneurship education, curriculum and practice system can be categorized into basic module, 
elite module and incubation module.

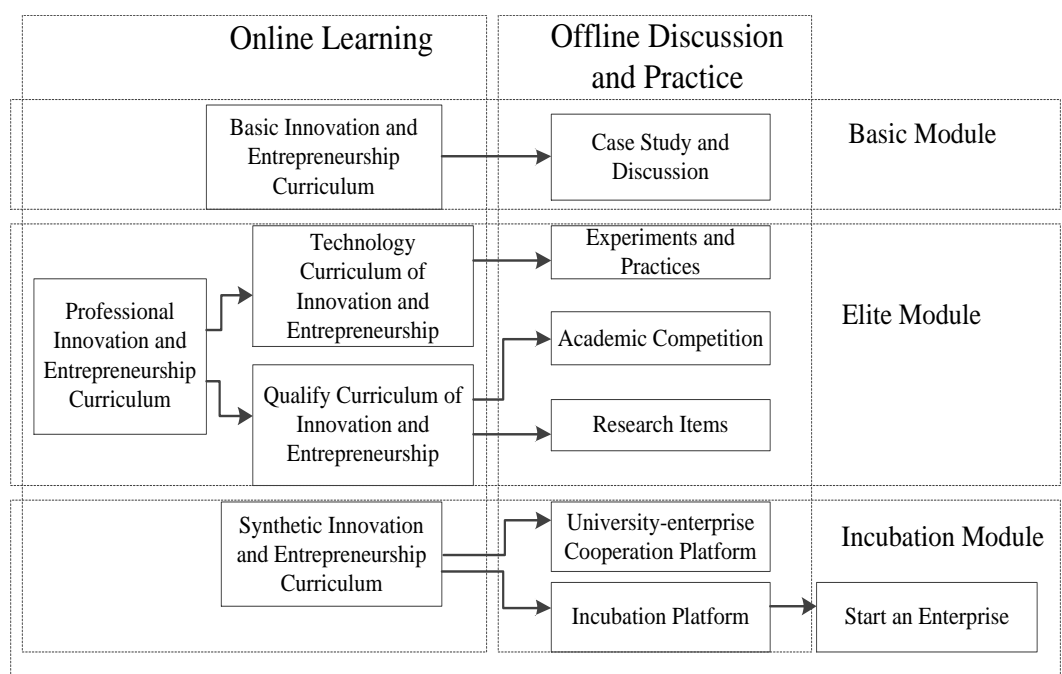

Figure 1. Finite Curriculum and practice system of innovation and entrepreneurship education incorporating SPOCs platform

Teaching Methods. In SPOCs platform, many new teaching methods can be incorporated in innovation and entrepreneurship curriculum. Compared to the traditional teaching methods, these new ones are student-center and can improve the student's active learning abilities. According to the teaching objective of innovation and entrepreneurship education, flipped classroom, blended learning and action learning can be introduced in innovation and entrepreneurship curriculum.

Flipped classroom is a classroom that swaps the arrangement of knowledge imparting and knowledge internalization comparing to traditional classroom[19]. In flipped classroom, students can self-learn the basic knowledge of innovation and entrepreneurship in SPOCs platform anytime and anywhere. In classroom, students can make discussion and practice under the guidance of teachers.In recent years, flipped classroom widely applied in higher education reform at home and abroad.

Blended learning is a method to combine online and face to face tuition[20]. In blended learning, we can maximum the advantages of SPOCs platform and traditional teaching methods such as case study, group discussion, module learning and etc, to improve the quality of innovation and entrepreneurship curriculum . Blended learning not only arouses the guidance and monitor role of teacher, but also inspires the initiation, enthusiasm and creativity of student.

Action learning is a method widely used in training institutions and enterprises, which is considered to be an effective way to cultivate innovation and entrepreneurship talents. In action learning classroom, the innovation and entrepreneurial projects in enterprise or industry can be introduced into the classroom, and the members in innovation and entrepreneurship teaching team can play the role of catalysis, who can promote the rigor of thinking and depth of thinking by showing the potential process of thinking on the desktop.

Evaluation Mechanism. In order to assess the effect of innovation and entrepreneurship education, an evaluation mechanism should be constructed. In accordance with comprehensive, systematic, operability principles and our preliminary investigation, an evaluation index system based on SPOCs is built up in Table 1. 
Table 1 Evaluation index system of innovation and entrepreneurship education

\begin{tabular}{|c|c|}
\hline Primary Index & Secondly Index \\
\hline \multirow{4}{*}{ Profession Ability } & Profession Knowledge \\
\cline { 2 - 3 } & Profession Skill \\
\cline { 2 - 3 } Innovation & Profession Extension \\
\cline { 2 - 2 } Ability & Autonomous Learning Ability \\
\cline { 2 - 3 } & Critical Analysis Ability \\
\cline { 2 - 3 } & Divergent Thinking \\
\hline \multirow{4}{*}{$\begin{array}{c}\text { Entrepreneurship } \\
\text { Ability }\end{array}$} & Innovation Achievements \\
\cline { 2 - 3 } & Management \\
\cline { 2 - 3 } & Ability \\
\cline { 2 - 3 } & Negotiation and Communication Skills \\
\cline { 2 - 3 } & Decision Action Ability \\
\cline { 2 - 3 } & Influence Ability \\
\cline { 2 - 2 } & Entrepreneurial Consciousness \\
\hline
\end{tabular}

\section{Conclusion}

In this paper, we integrate the SPOCs platform into the process of innovation and entrepreneurship education in Colleges and universities, so as to give full play to the characteristics of the SPOCs platform, and promote the further development of innovation and entrepreneurship education in Colleges and universities. From the practical point of view, innovation and entrepreneurship education model based on the SPOCs platform can effectively promote the teacher-student interaction and the thinking and analysis of students, help students innovative thinking and entrepreneurship ability of growth.

\section{Acknowledgements}

This paper is supported by the research project of educational technology in Zhejiang Province (JB048) .

\section{Reference}

[1] Fox A. From MOOCs to SPOCs[J]. Communications of the Acm, 2013, 56(12):38-40.

[2] Burge J, Fox A, Grossman D, et al. SPOCs: What, Why, and How[C]ACM Technical Symposium on Computer Science Education. ACM, 2015:595-596.

[3] Jiang S. MOOCs and SPOCs:The Different Paths and Common Problems of the Online Course Development[J]. Journal of Distance Education, 2014.

[4] Yin HD, Exploration of Blended Teaching Model based on Fanya SPOC Platform during the Post-MOOC Period[J]. Modern Educational Technology, 2015, 25(11):53-59.

[5] Li L. MOOCs and SPOCs: Evolution and Inheritance of Online Education[C] International Conference on Education, Management, Computer and Society. Atlantis Press, 2016.

[6] Lin XF, Hu Q, Deng CL. Research on the innovation ability cultivation mode based on SPOC[J]. e-Education Research, 2015(10):46-51. 
[7] Root Kustritz M V. Canine theriogenology for dog enthusiasts: teaching methodology and outcomes in a massive open online course (MOOC).[J]. Journal of Veterinary Medical Education, 2014, 41(1):1-10.

[8] Kulkarni C, Wei K P, Le H, et al. Peer and Self Assessment in Massive Online Classes[J]. ACM Transactions on Computer-Human Interaction, 2013, 20(6):131-168.

[9] Delgado Kloos C, Muñozmerino P J, Ruipérezvaliente J A, et al. A Successful Learning Experience using SPOCs[J]. 2014.

[10]Fox A, David Patterson,Richard Ilson, et al. Software Engineering Curriculum Technology Transfer:Lessons learned from MOOCs and SPOCs, 2014:1-6.

[11]Chu C C, Hung S, Chang C H, et al. Applying SPOCs for Programming Course to Improve Study Quality[C] International Conference on Trustworthy Systems and Their Applications. 2015 .

[12]Liu J. Connotation, Problems and Reform Path of Innovation and Entrepreneurship Education in Universities[J]. Journal of Higher Education, 2016(10):31-32.

[13] Wu YJ, Dilemma and Path Selection of Innovation and Entrepreneurship Education Reform in Universities[J]. Education Exploration, 2015(11):63-66.

[14]Jiao L, Wang X. Construction of Practical System of Innovation and Entrepreneurship Education in Chinese Universities[J]Journal of Liaoning Educational Administration Institute, 2015(2):46-49.

[15] Chen Y. Construction of Innovation and Entrepreneurship Education system in Universities in the New Era[J]. Asia Pacific Education,2016(15):170-170.

[16] Chang JQ. Analysis of the Innovation and Entrepreneurship Education System in American Universities and Its Enlightenment to China[J]. Journal of Heilongjiang College of Education, 2008, 27(10):49-50.

[17]Dirk Reichelt. Exploration of Industry 4.0 for Innovation and Entrepreneurship in Germany Universities[J]. Journal of China University of Metrology, 2015, 26(4):394-398.

[18] Yu M. Analysis and Reference of Innovation and Entrepreneurship Education in Japanese Universities[C]. Liaoning Provincial Institute of Higher Education Annual forum,2015. 